\title{
Perception of Special Teachers on the Evidence based Intervention Strategies for Children with Autism Spectrum Disorder
}

\author{
Rajesh Ramachandran, J. Sujathamalini
}

\begin{abstract}
Autism Spectrum Disorder (ASD) is one of five developmental disorders, it is a complex neurodevelopmental disorder affecting the ability of the person to socialize, communicate along with stereotype behaviours. ASD can affect any person irrespective of the gender, caste, creed or religion. Intervention means doing something, taking action or using a treatment to try to improve a particular condition or a problem. When it comes to ASD, there are many kinds of interventions offered. Depending on the type, they can involve the child, the parent or both.

They might be one-off events or involve many sessions spread over years. Interventions are based on different theories about what causes ASD. The current study which is a part of the PhD tries to study the perception of special teachers on the current Intervention strategies for children with ASD. The study was conducted by circulating the questionnaire developed to the special teachers $(n=40)$ working for $A S D$ in the country. The participants consisted of special teachers having Diploma, Degree) and Post Graduate degree in the field of ASD $(n=40)$. Descriptive statistics; frequency, percentages, and chi square tests were done using SPSS. The results indicated that teachers accepted the need for evidence based intervention strategies for training children with ASD.
\end{abstract}

Keywords: Autism Spectrum Disorder, Perception, Intervention strategies.

\section{I.INTRODUCTION}

The word Autism comes from the Greek word autos meaning self. Autism spectrum disorder (ASD) is a group of developmental disabilities that can cause significant social, communication and behavioural challenges. (CDC). About 1 in 59 children has been identified with autism spectrum disorder (ASD) according to estimates from CDC's Autism and Developmental Disabilities Monitoring (ADDM) Network, which means in India there are over 18 million people with autism spectrum disorder (AFA).

The historical roots of autism can be traced down during the sixteenth century. During that period some respected people in ancient Russia were considered as the 'holy fools'. These individuals were reported to be eccentric, given to parroting, with stereotypic speech and actions, obsessive interests, and lack of social awareness (RCI). Though official journey of Autism started 74 years back, with Dr. Leo Kanner identifying the characteristics of 11 individuals reported to

Revised Manuscript Received on October 25, 2019

Rajesh Ramachandran, (PhD Research Scholar), Department of Special Education \& Rehabilitation Science, Alagappa University, Karaikudi

Dr. J. Sujathamalini, (Associate Prof. \& Head (i/c) ), Department of Special Education \& Rehabilitation Science, Alagappa University, Karaikudi his clinic. From that year onwards various professionals started working on improving abilities among children with ASD. Cognitive abilities in people with ASD vary between those with average to above average intelligence, to borderline and mild intellectual disability, and others who function within the range of moderate to profound intellectual disability.

Training of an individual using scientifically based intervention strategies is a necessity and more so necessary after the enactment of RPwD Act 2016. Though there are many interventions coming up, for that matter if you search in Google about interventions in Autism, there are many but lack support from the scientific fraternity. In fact, due to the use of non-scientific interventions growth of the effective scientific based interventions for individuals having Autism is getting impeded (Rajesh \& Sujatha 2018).

There are many scientifically based intervention strategies which can be very well understood by the following table adapted from Autism Spectrum Disorders- Intervention \& Treatments for children and youth, Richard L Simpson 2005, 2008

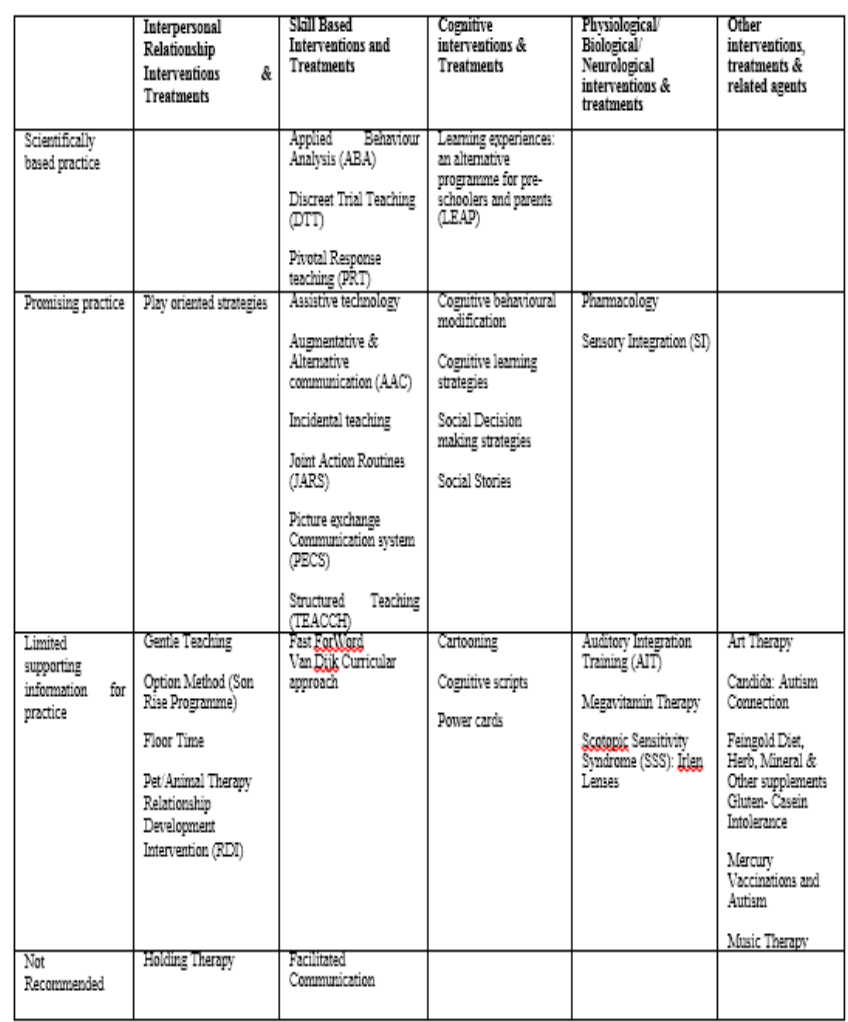




\section{REVIEW OF LITERATURE}

Reviewing literature is important as it substantiates the current knowledge and findings in relation to the study. Understanding perception of Special teachers with regard to the evidence based interventional strategies for children with ASD is important because effective intervention provided by the teacher in the classroom will improve the abilities of the child with ASD, which will go a long way in empowering them.

Stidham, K. M (2016) did a web based survey of 108 general education teachers with regard to their perception about educating students with ASD in an inclusive classroom, the results of the study revealed that there were no significant relationships between the teacher's perception and teachers training on autism. However, the general teachers felt that further training about the interventional strategies can better their learning in understanding the characteristics of children having ASD.

Strong, $\boldsymbol{J} \boldsymbol{E}$ (2014) analysed data based on field observations and interviews from teachers who completed their professional training in ASD and examined perception of the teachers and relationships between their knowledge and self-acquisition and self-efficacy.

Hansen, $K$ L (2015) evaluated perceived versus actual knowledge of ASD among undergraduate students, interestingly the current study found no significant interaction between self-efficacy, perceived knowledge of ASD, and actual knowledge of ASD.

\section{HYPOTHESIS}

1. No difference in perception among teachers having diploma, degree and post graduate qualification towards current intervention strategies among children with ASD

2. No difference in perception among male teachers having diploma, degree and post graduate qualification towards current intervention strategies among children with ASD

3. No difference in perception among female teachers having diploma, degree and post graduate qualification towards current intervention strategies among children with ASD

4. No difference in perception among teachers having diploma, degree and post graduate qualification along with years of experience towards current intervention strategies among children with ASD

\section{METHODOLOGY}

Descriptive research design was adopted for the study. A Likert scale on assessing the perception of the special teachers on the intervention strategies being used for children with Autism Spectrum Disorder was developed and was validated. A comprehensive review of literature was done to understand the perception of teachers working with children having Autism Spectrum Disorder in special and Normal schools. Furthermore the guidance of the research guide was sought for pooling the items. The scale developed was converted into Google form and was sent to the Special educators /teachers who have completed required qualification in the field of ASD. The data received was coded. Sample size: a total of 40 teachers were provided with the scale through convenient sampling method.

Table 2

\begin{tabular}{|l|l|}
\hline Qualification & No of teachers \\
\hline D. Ed SE (ASD) & 32 \\
\hline B. Ed SE (ASD) & 4 \\
\hline M. Ed SE (ASD) & 4 \\
\hline Total & 40 \\
\hline
\end{tabular}

\section{RESULTS \& DISCUSSION}

Hypothesis - No significant difference in perception among teachers having diploma, degree and post graduate qualification towards current intervention strategies among children with ASD

Q.1 Intervention strategies for children with Autism spectrum Disorder (ASD) can be used effectively in individual setting rather than group settings?

Table 3

\begin{tabular}{|l|l|l|}
\hline & Frequency & Percent \\
\hline Agree & 21 & 52.5 \\
Neutral & 2 & 5 \\
Slightly agree & 13 & 32.5 \\
Slightly & & \\
disagree & 4 & 10 \\
Total & 40 & 100 \\
\hline
\end{tabular}

Among the total teachers $52.5 \%$ agree, $5 \%$ are neutral $32.5 \%$ of teachers slightly agreed and $10 \%$ of teachers slightly disagree. Majority of the teachers agree with intervention strategies for children with ASD can be used effectively in individual setting

Q.2 Children with ASD will learn effectively in structured setting?

Table 4

\begin{tabular}{|l|l|l|}
\hline & Frequency & Percent \\
\hline Agree & 23 & 57.5 \\
Disagree & 1 & 2.5 \\
Neutral & 2 & 5 \\
Slightly agree & 13 & 32.5 \\
Slightly disagree & 1 & 2.5 \\
Total & 40 & 100 \\
\hline
\end{tabular}

This table shows $57.5 \%$ of teachers agree, $2.5 \%$ disagree, neutral $5.0 \%$, slightly agree $32.5 \%$ and $2.5 \%$ slightly disagree. Majority of the participants agreed that with Children with ASD will learn effectively in structured 
setting. Structured teaching is based on TEACCH approach, which is a promising intervention strategy with scientific evidences.

Q.3 Children with ASD will learn better through Visual Schedule!

Table 5

\begin{tabular}{|l|l|l|}
\hline & Frequency & Percent \\
\hline Agree & 28 & 70.0 \\
Neutral & 1 & 2.5 \\
Slightly agree & 11 & 27.5 \\
Total & 40 & 100.0 \\
\hline
\end{tabular}

This table shows that among total teachers answered, $70 \%$ of them agreed, $2.5 \%$ are neutral and $27.5 \%$ of participants slightly agree, which means that if children with ASD provided with a visual schedule they learn better.

Q.4 ABA as an intervention Strategies is better for children with ASD

Table 6

\begin{tabular}{|l|l|l|}
\hline & Frequency & Percent \\
\hline Agree & 23 & 57.5 \\
Neutral & 4 & 10.0 \\
Slightly agree & 9 & 22.5 \\
Slightly Disagree & 4 & 10.0 \\
Total & 40 & 100.0 \\
\hline
\end{tabular}

Here total teacher $57.5 \%$ agreed, $10 \%$ of the teachers are neutral, $22.5 \%$ of teachers slightly agree and $10 \%$ of teachers slightly disagree. Majority of the teachers agree with the ABA as an intervention Strategies is better for children with ASD. Mary Jane Weiss, Kate Fiske \& Suzannah Ferraioli (2008) in their article on Evidence based practices for Autism spectrum disorder highlighted that Applied Behaviour Analysis (ABA) has greater facts supporting the effectiveness of intervention in Autism. They also mentioned that evidence exists for the Lovaas/UCLA comprehensive treatment package, but more scientific evidences are required to support this intervention strategy.

Q.5 Picture exchange communication system (PECS) can help in improving the communication of children with ASD Table 7

\begin{tabular}{|l|l|l|}
\hline & Frequency & Percent \\
\hline Agree & 35 & 87.5 \\
Neutral & 1 & 2.5 \\
Slightly agree & 2 & 5.0 \\
Slightly Disagree & 2 & 5.0 \\
Total & 40 & 100.0 \\
\hline
\end{tabular}

$87.5 \%$ of the teachers agreed, $2 \%$ of the teachers are neutral, $5 \%$ of teachers slightly agree and $5 \%$ of teacher

slightly disagrees. Majority of the teachers agrees with the Picture exchange communication system (PECS) can help in improving the communication of children with ASD

Q.6 Discreet Trail Training (DTT) can increase the skills deficit behaviour among children with ASD Table 8

\begin{tabular}{|l|l|l|}
\hline & Frequency & Percent \\
\hline Agree & 14 & 35.0 \\
Neutral & 8 & 20.0 \\
Slightly agree & 14 & 35.0 \\
Slightly Disagree & 4 & 10.0 \\
Total & 40 & 100.0 \\
\hline
\end{tabular}

Among total teachers $35 \%$ agrees, $20 \%$ of the teachers are neutral, $35 \%$ of teachers slightly agree and $10 \%$ of teachers slightly disagree. Majority of the participants agrees with the Discreet Trail Training (DTT) can increase the skills deficit behaviour among children with ASD, $20 \%$ of the teachers who gave neutral as their response on further enquiry felt that not much information is provided on DTT during their training.

Q.7 Pivotal Response Training (PRT) helps to increase social skills, communication skills, behaviour and learning skills among children with ASD

Table 9

\begin{tabular}{|l|l|l|}
\hline & Frequency & Percent \\
\hline Agree & 16 & 40.0 \\
Neutral & 13 & 32.5 \\
Slightly agree & 10 & 25.0 \\
Slightly Disagree & 1 & 2.5 \\
Total & 40 & 100.0 \\
\hline
\end{tabular}

$40 \%$ of the teachers agree, $32 \%$ of the teachers are neutral, $25 \%$ of teachers slightly agree and $2.5 \%$ of teachers slightly disagree. Majority agreed with the Pivotal Response Training (PRT) helps to increase social skills, communication skills, behaviour and learning skills among children with ASD. Pierce, K., \& Schreibman, L. (1995) in their study on Effects of peer-implemented pivotal response training in increasing complex social behaviours in children with autism, children with autism maintained prolonged interactions with the peer and initiated play and conversations, along with increased engagement in language and joint attention behaviours.

Q.8 Learning experience and alternate programmes for pre-schoolers and their parents (LEAP) will help increase the social and communication skills of children with ASD 
Table 10

\begin{tabular}{|l|l|l|}
\hline & Frequency & Percent \\
\hline Agree & 17 & 42.5 \\
Neutral & 10 & 25.0 \\
Slightly agree & 13 & 32.5 \\
Total & 40 & 100.0 \\
\hline
\end{tabular}

The results shows that Majority of the teachers agreed with the Learning experience and alternate programmes for pre-schoolers and their parents (LEAP) which will help increase the social and communication skills of children with ASD

\section{Q.9 Augmentative \& Alternative Communication}

(AAC) helps the child with ASD to use communicative skills more effectively

Table 11

\begin{tabular}{|l|l|l|}
\hline & Frequency & Percent \\
\hline Agree & 29 & 72.5 \\
Disagree & 2 & 5.0 \\
Neutral & 3 & 7.5 \\
Slightly agree & 6 & 15.0 \\
Total & 40 & 100.0 \\
\hline
\end{tabular}

Among total teachers $72.5 \%$ of the teacher agrees, $5 \%$ of the teachers disagree, $7.5 \%$ of teachers are neutral and $15 \%$ of the teachers slightly agree. Majority of the teachers agrees with the Augmentative \& Alternative Communication (AAC) which helps the child with ASD to use communicative skills more effectively

Q.10 Functional Communication Training (FCT) helps the child with ASD improve communication

Table 12

\begin{tabular}{|l|l|l|}
\hline & Frequency & Percent \\
\hline Agree & 15 & 37.5 \\
Disagree & 4 & 10.0 \\
Neutral & 9 & 22.5 \\
Slightly agree & 9 & 22.5 \\
Slightly Disagree & 3 & 7.5 \\
Total & 40 & 100.0 \\
\hline
\end{tabular}

Most of the teachers $37.5 \%$ agree that Functional Communication Training (FCT) helps the child with ASD improve communication

Q.11 Language acquisition through motor planning (LAMP) a proven therapeutic approach, increase the expressive abilities of children with ASD

\begin{tabular}{|l|l|l|}
\hline & Frequency & Percent \\
\hline Agree & 13 & 32.5 \\
Disagree & 1 & 2.5 \\
Neutral & 13 & 32.5 \\
Slightly agree & 12 & 30.0 \\
Slightly Disagree & 1 & 2.5 \\
Total & 40 & 100.0 \\
\hline
\end{tabular}

$32.5 \%$ of the teachers agree but similar $32.5 \%$ teacher responses were neutral due to insufficient information about the strategy on LAMP.

Q.12 The Comic script conversations helps children with ASD to practice the new vocabulary words

Table 14

\begin{tabular}{|l|l|l|}
\hline & Frequency & Percent \\
\hline Agree & 23 & 57.5 \\
Neutral & 8 & 20.0 \\
Slightly agree & 9 & 22.5 \\
Total & 40 & 100.0 \\
\hline
\end{tabular}

Majority of the teachers agree with the Comic script conversations that helps children with ASD to practice the new vocabulary words

Q.13 Joint Action routines (JARS) encourages communications skills in children with ASD

Table 15

\begin{tabular}{|l|l|l|}
\hline & Frequency & Percent \\
\hline Agree & 25 & 62.5 \\
Neutral & 9 & 22.5 \\
Slightly agree & 5 & 12.5 \\
Slightly Disagree & 1 & 2.5 \\
Total & 40 & 100.0 \\
\hline
\end{tabular}

$62.5 \%$ of the teachers agree with the Joint Action routines (JARS) which is shown to encourage communications skills in children with ASD

Q.14 Sensory integration therapy (SIT) helps children with ASD to integrate sensory dysfunction

Table 16

\begin{tabular}{|l|l|l|}
\hline & Frequency & Percent \\
\hline Agree & 30 & 75.0 \\
Neutral & 1 & 2.5 \\
Slightly agree & 9 & 22.5 \\
Total & 40 & 100.0 \\
\hline
\end{tabular}


$75 \%$ of the teachers agreed that Sensory integration therapy (SIT) helps children with ASD to integrate sensory dysfunction

Q.15 Children with ASD will show improved performance with Co-teaching

Table 17

\begin{tabular}{|l|l|l|}
\hline & Frequency & Percent \\
\hline Agree & 18 & 45.0 \\
Neutral & 9 & 22.5 \\
Slightly agree & 9 & 22.5 \\
Slightly Disagree & 4 & 10.0 \\
Total & 40 & 100.0 \\
\hline
\end{tabular}

$45 \%$ of the teacher agreed with the statement that Children with ASD will show improved performance with Co-teaching.

Q.16 Social stories help children with ASD to improvise social and communication skills

Table 18

\begin{tabular}{|l|l|l|}
\hline & Frequency & Percent \\
\hline Agree & 27 & 67.5 \\
Disagree & 1 & 2.5 \\
Neutral & 2 & 5.0 \\
Slightly agree & 10 & 25.0 \\
Total & 40 & 100.0 \\
\hline
\end{tabular}

$67.5 \%$ of the teachers agreed that the Social stories help children with ASD to improvise social and communication skills as studied by Al zyoudi, Mohammed; et.al (2016) wherein they evaluated the effectiveness of using a social story intervention among three students having children between the age range of 7-8 years with autism. The results indicated improvement in social interaction for all children.

Q.17 Floor time play based intervention helps children with ASD to master functional emotional development

Table 19

\begin{tabular}{|l|l|l|}
\hline & Frequency & Percent \\
\hline Agree & 18 & 45.0 \\
Disagree & 1 & 2.5 \\
Neutral & 8 & 20.0 \\
Slightly agree & 13 & 32.5 \\
Total & 40 & 100.0 \\
\hline
\end{tabular}

The table clearly indicates that majority of the participants agrees with the Floor time play based intervention strategy which helps children with ASD to master functional emotional development
Q.18. Son Rise option methods has been proved to improve social skills, communication skills \& cognitive skills

Table 20

\begin{tabular}{|l|l|l|}
\hline & Frequency & Percent \\
\hline Agree & 7 & 17.5 \\
Disagree & 2 & 5.0 \\
Neutral & 16 & 40.0 \\
Slightly agree & 15 & 37.5 \\
Total & 40 & 100.0 \\
\hline
\end{tabular}

Since there is a limited supporting information for practice related to Son Rise option method most of the teachers did not respond to the question and they gave their responses as neutral.

Q.19 The relationship between parent and child with ASD will improve by Relationship Based Intervention which in turn improves brain function

Table 21

\begin{tabular}{|l|l|l|}
\hline & Frequency & Percent \\
\hline Agree & 10 & 25.0 \\
Neutral & 12 & 30.0 \\
Slightly agree & 14 & 35.0 \\
Slightly Disagree & 4 & 10.0 \\
Total & 40 & 100.0 \\
\hline
\end{tabular}

Since there is a limited supporting information for practice related to Relationship based intervention most of the teachers responded by slightly agreeing to the question

Q.20 Gentle teaching helps the child with ASD to acquire social competence

Table 22

\begin{tabular}{|l|l|l|}
\hline & Frequency & Percent \\
\hline Agree & 16 & 40.0 \\
Disagree & 4 & 10.0 \\
Neutral & 12 & 30.0 \\
Slightly agree & 4 & 10.0 \\
Slightly Disagree & 4 & 10.0 \\
Total & 40 & 100.0 \\
\hline
\end{tabular}

Majority of the teachers agreed that Gentle teaching helps the child with ASD to acquire social competence.

Hypothesis 2; No difference in perception among male teachers having diploma, degree and post graduate qualification towards current intervention strategies among children with ASD

Hypothesis 3; No difference in perception among female teachers having diploma, degree and post graduate qualification towards current

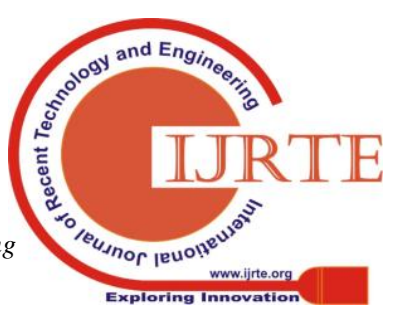


Perception of Special Teachers on the Evidence based Intervention Strategies for Children with Autism Spectrum Disorder

intervention strategies among children with ASD

The table mentioned below shows the results with reference to the gender (male and Female)

Table 23

Chi square Tests

\begin{tabular}{|c|c|c|c|c|c|}
\hline Gender & \multicolumn{2}{|c|}{ Valid } & \multicolumn{3}{|c|}{ Chi square Tests } \\
\hline & N & Percent & P value & Df & $\begin{array}{c}\text { Chi square } \\
\text { value }\end{array}$ \\
\hline Q1 & 40 & $100.0 \%$ & $6.113^{\mathrm{a}}$ & 3 & .106 \\
\hline Q2 & 40 & $100.0 \%$ & .194 & 4 & 6.076 \\
\hline Q3 & 40 & $100.0 \%$ & 1.866 & 2 & .393 \\
\hline Q4* & $\mathbf{4 0}$ & $\mathbf{1 0 0 . 0 \%}$ & $\mathbf{. 0 3 8}$ & $\mathbf{3}$ & $\mathbf{8 . 4 2 3}$ \\
\hline Q5 & 40 & $100.0 \%$ & .160 & 3 & 5.170 \\
\hline Q6 & 40 & $100.0 \%$ & .343 & 3 & 3.337 \\
\hline Q7 & 40 & $100.0 \%$ & .710 & 3 & 1.380 \\
\hline Q8 & 40 & $100.0 \%$ & .080 & 2 & 5.060 \\
\hline Q9 & 40 & $100.0 \%$ & .359 & 3 & 3.218 \\
\hline Q10* & $\mathbf{4 0}$ & $\mathbf{1 0 0 . 0 \%}$ & $\mathbf{. 0 3 4}$ & $\mathbf{4}$ & $\mathbf{1 0 . 4 1 5}$ \\
\hline Q11 & 40 & $100.0 \%$ & .152 & 4 & .6712 \\
\hline Q12 & 40 & $100.0 \%$ & .757 & 2 & .556 \\
\hline Q13 & 40 & $100.0 \%$ & .543 & 3 & 2.145 \\
\hline Q14 & 40 & $100.0 \%$ & .386 & 2 & 1.905 \\
\hline Q15 & 40 & $100.0 \%$ & .259 & 3 & 4.021 \\
\hline Q16 & 40 & $100.0 \%$ & .341 & 3 & 3.345 \\
\hline Q17 & 40 & $100.0 \%$ & .687 & 3 & 1.481 \\
\hline Q18 & 40 & $100.0 \%$ & .407 & 3 & 2.900 \\
\hline Q19 & 40 & $100.0 \%$ & .651 & 3 & 1.637 \\
\hline Q20 & 40 & $100.0 \%$ & .829 & 4 & 1.487 \\
\hline
\end{tabular}

The question no. 4 shows the $\mathrm{P}$ value as 0.038 which indicates that there is association between male and female teachers. Similarly question no. 10 shows the $\mathrm{P}$ value as 0.034 , which indicates association between the two variables. Hypothesis 4- No association in perception among teachers having diploma, degree and post graduate qualification along with years of experience towards evidence based intervention strategies among children with ASD

\section{Chi square Tests}

Table 24

\begin{tabular}{|l|r|r|r|r|r|}
\hline Qualification & \multicolumn{2}{|c|}{ Valid } & \multicolumn{3}{c|}{ Chi square Tests } \\
\hline & \multicolumn{1}{|c|}{$\mathrm{N}$} & \multicolumn{1}{|c|}{ Percent } & P value & Df & $\begin{array}{c}\text { Chi square } \\
\text { value }\end{array}$ \\
\hline Q1 & 40 & $100.0 \%$ & .343 & 6 & 6.765 \\
\hline Q2 & 40 & $100.0 \%$ & .450 & 8 & 7.837 \\
\hline Q3 & 40 & $100.0 \%$ & .585 & & 2.841 \\
\hline
\end{tabular}

\begin{tabular}{|l|r|r|r|r|r|}
\hline Q4 & 40 & $100.0 \%$ & .572 & 6 & 4.783 \\
\hline Q5 & 40 & $100.0 \%$ & .964 & 6 & 1.429 \\
\hline Q6* & $\mathbf{4 0}$ & $\mathbf{1 0 0 . 0 \%}$ & $\mathbf{. 0 3 8}$ & $\mathbf{6}$ & $\mathbf{1 3 . 3 2 1}$ \\
\hline Q7 & 40 & $100.0 \%$ & .755 & 6 & 3.415 \\
\hline Q8* & $\mathbf{4 0}$ & $\mathbf{1 0 0 . 0 \%}$ & $\mathbf{. 0 0 6}$ & $\mathbf{4}$ & $\mathbf{1 4 . 6 0 4}$ \\
\hline Q9 & 40 & $100.0 \%$ & .429 & 6 & 5.948 \\
\hline Q10* & $\mathbf{4 0}$ & $\mathbf{1 0 0 . 0 \%}$ & $\mathbf{. 0 0 0}$ & $\mathbf{8}$ & $\mathbf{2 8 . 1 1 1}$ \\
\hline Q11 & 40 & $100.0 \%$ & .865 & 8 & 3.910 \\
\hline Q12 & 40 & $100.0 \%$ & .256 & 4 & 5.319 \\
\hline Q13 & 40 & $100.0 \%$ & .717 & 6 & 3.700 \\
\hline Q14* & $\mathbf{4 0}$ & $\mathbf{1 0 0 . 0 \%}$ & $\mathbf{. 0 4 1}$ & $\mathbf{4}$ & $\mathbf{9 . 9 5 8}$ \\
\hline Q15 & 40 & $100.0 \%$ & .079 & 6 & 11.319 \\
\hline Q16 & 40 & $100.0 \%$ & .271 & 6 & 7.579 \\
\hline Q17 & 40 & $100.0 \%$ & .590 & 6 & 4.642 \\
\hline Q18 & 40 & $100.0 \%$ & .655 & 6 & 4.161 \\
\hline Q19 & 40 & $100.0 \%$ & .761 & 6 & 3.372 \\
\hline Q20* & $\mathbf{4 0}$ & $\mathbf{1 0 0 . 0 \%}$ & $\mathbf{. 0 2 7}$ & $\mathbf{8}$ & $\mathbf{1 7 . 2 6 6}$ \\
\hline & & & & & \\
\hline
\end{tabular}

In the following table question no. 6 shows the $\mathrm{P}$ value as 0.038 which indicates that there is association between qualification of the teachers and Discreet Trail Training (DTT) which the teachers perceive that it can Increase the Skills Deficit Behaviour among Children with ASD Similarly question no. 8, 14 and 20 indicating the $P$ values as $0.006,0.041,0.027$ respectively indicating association between the two variables.

Table 25

\section{Chi square Tests}

\begin{tabular}{|l|r|r|r|r|r|}
\hline \multirow{2}{*}{$\begin{array}{c}\text { Experie } \\
\text { nce }\end{array}$} & \multicolumn{2}{|c|}{ Valid } & \multicolumn{3}{|c|}{ Chi square Tests } \\
\cline { 2 - 6 } & N & Percent & P value & Df & $\begin{array}{c}\text { Chi square } \\
\text { value }\end{array}$ \\
\hline Q1 & 40 & $100.0 \%$ & .415 & 9 & 9.241 \\
\hline Q2 & 40 & $100.0 \%$ & .735 & 12 & 8.617 \\
\hline Q3 & 40 & $100.0 \%$ & .081 & 6 & 11.243 \\
\hline Q5 & 40 & $100.0 \%$ & .578 & 9 & 7.567 \\
\hline Q6 & 40 & $100.0 \%$ & .488 & 9 & 8.469 \\
\hline Q7 & 40 & $100.0 \%$ & .042 & 9 & 17.464 \\
\hline Q8 & 40 & $100.0 \%$ & .182 & 9 & 12.598 \\
\hline Q9 & 40 & $100.0 \%$ & .130 & 6 & 9.885 \\
\hline Q10 & 40 & $100.0 \%$ & .578 & 9 & 7.567 \\
\hline Q11 & 40 & $100.0 \%$ & .291 & 12 & 14.152 \\
\hline Q12 & 40 & $100.0 \%$ & .074 & 6 & 11.485 \\
\hline Q13 & 40 & $100.0 \%$ & .254 & 9 & 11.328 \\
\hline Q14 & 40 & $100.0 \%$ & .654 & 6 & 4.169 \\
\hline Q15 & 40 & $100.0 \%$ & .061 & 9 & 16.290 \\
\hline Q16 & 40 & $100.0 \%$ & .456 & 9 & 8.702 \\
\hline Q17 & 40 & $100.0 \%$ & .155 & 9 & 13.168 \\
\hline Q18 & 40 & $100.0 \%$ & .061 & 9 & 16.312 \\
\hline Q19 & 40 & $100.0 \%$ & .357 & 9 & 9.922 \\
\hline Q20 & 40 & $100.0 \%$ & .070 & 12 & 19.841 \\
\hline & & & 269 & 12 & 14.521 \\
\hline
\end{tabular}


The question no. 6 shows the $\mathrm{P}$ value as 0.042 which indicates that there is association between experience of the teachers and Discreet Trail Training (DTT), the experienced teachers agree that DTT can increase the Skills Deficit Behaviour among Children with ASD indicating association between the two variables.

\section{FOCUSSED GROUP DISCUSSION}

A group of 5 special teachers working for children with Autism spectrum disorder at the Model school of NIEPMD were discussed with the evidence based intervention strategies used for children with autism spectrum disorder and their views were explored. The participants consisted of 2 female special teachers and 3 male special teachers of which one special teacher was having the qualification of M. Ed Special Education (Autism Spectrum Disorder)

\section{Major points constructed from the focussed group discussion}

The teachers opined that children with Autism spectrum disorder learn better with structured teaching which is based on the principle of TEACCH, that involves physical restructuring, providing visual schedules for the activities to be taught. Structured teaching is an approach which helps individual with autism spectrum disorder comprehend the surroundings in which they perform daily activities using by using visual mode, that is considered to be their strongest technique. The teachers felt that though ABA is scientifically based skill based intervention which can be practiced in one to one situations may not be sometimes feasible in a country like ours, where, in a special school there are 4 to 5 children with autism spectrum disorder with different level of autism. The teachers expressed that children with autism spectrum disorder should also regularly attend speech and language therapy session and also sensory integration therapy (SIT)

\section{DISCUSSION}

$87.5 \%$ of teachers said that Picture exchange Communication system (PECS) is more effective in terms of teaching communication along with a picture of a desired item to child with autism spectrum disorder. PECS has proven scientifically as a promising practice. $75.0 \%$ of teacher agreed that sensory integration therapy (SIT) is helpful to tackle sensory related issues in children with autism spectrum disorder, $72.5 \%$ of teachers accepted that teaching Augmentative \& Alternative communication (AAC) is helpful to improve the communicating skills through alternative modes of communication among children with autism. $70 \%$ of the teachers agreed that teaching Visual schedule will help the children with autism spectrum disorder in improves the schedule patterned life style. $67.5 \%$ of the teacher said teaching social stories (SS) is will help the children with ASD in improving social skills

\section{CONCLUSION}

Awareness about ASD has gained momentum and due to this there has been proper diagnosis of ASD. As a result of this the Rehabilitation Council of India (RCI) started courses in the field of ASD. The curriculum content was designed incorporating evidence based intervention strategies. This helped in making the teachers understand the need for educating and empowering children with ASD in a more scientific manner. Hendricks (2012) in his study found that special education teachers who work with students with ASD have intermediate levels of knowledge of the disorder and effective instructional practices for students with ASD. Meanwhile many intervention strategies have been added which lacks proper representation from the scientific fraternity. Most of the intervention strategies bear a tagline of the European countries and indigenous strategies are still being worked out.

The results here reveal that most of the teachers qualified in the field of ASD feel the need to have evidence based intervention strategies and that there is association between the scientific practice, promising practice of intervention strategies than to the intervention strategies that have limited supporting information for practice. So basically the research should help the teachers or the special educators to select intervention strategies based on evidences which in turn be implemented by them towards improving the child with ASD (Lubas, M, Mitchell, J\&L Leo, $G$ D (2015).

\section{ACKNOWLEDGEMENT}

The authors would like to thank the Vice Chancellor of Alagappa University Prof. N. Rajendran for his continuous support. The authors would also like to thank Assistant Prof. Dr. K. Gunasekaran and all the teachers who responded to the questions. Thanks are due to Ms. C. Kayalvizhi and Ms. M. Shylaja from NIEPMD for their support in compiling data.

\section{FINANCIAL SUPPORT AND SPONSORSHIP}

Since this is a part of $\mathrm{PhD}$ of the first author, there is no financial support and sponsorship received.

\section{CONFLICT OF INTEREST}

There are no conflicts of interest.

\section{REFERENCES}

[1]. Al zyoudi, Mohammed; et.al (2016). The Effectiveness of Using a Social Story Intervention to Improve Social Interaction Skills of Students with Autism. Journal of the American Academy of Special Education Professionals, p17-30 Win 2016 https://eric.ed.gov/?q=social+stories+\&id=EJ1129718

[2]. Carnahan, C. (2009). Structured teaching: Online training module (Columbus, OH: OCALI). In Ohio Center for Autism and Low Incidence (OCALI), Autism Internet Modules, www.autisminternetmodules.org. Columbus, OH: OCALI

[3]. Hansen, K L (2015). Development and Validation of a Survey of Knowledge of Autism Spectrum Disorder" (2015), Master's Theses. 141, retrieved from https://aquila.usm.edu/cgi/viewcontent.cgi?referer=https://www.google. com $/ \&$ httpsredir $=1 \&$ article $=1156 \&$ context=masters_theses

[4]. Hendricks, D. (2011). Special education teachers serving students with autism: A descriptive study of the characteristics and self-reported knowledge and practices employed. Journal of Vocational Rehabilitation, 35, 37-50. doi: 10.3233/JVR2011-0552 retrieved 
form

https://etd.ohiolink.edu/!etd.send_file?accession=dayton1437420783\&d isposition=inline

[5]. Margaret Lubas, Jennifer Mitchell, Gianluca De Leo (2015 Evidence-Based Practice for Teachers of Children with Autism A Dynamic Approach. Intervention in School and Clinic, v51 n3 p188-193 Jan 2016

[6]. Mary Jane Weiss, Kate Fiske \& Suzannah Ferraioli (2008). Evidence based practice in Autism Spectrum Disorders in Clinical Assessment and Intervention for Autism Spectrum Disorders (Practical Resources for Mental Health Professionals) edited by Johnny Matson published by Elsevier London ISBN 978-0-12-373606-2

[7]. Pierce, K., \& Schreibman, L. (1995). Increasing complex social behaviours in children with autism: Effects of peer-implemented pivotal response training. Journal of Applied Behaviour Analysis, 28, 285-295, retrieved

from https://www.ncbi.nlm.nih.gov/pmc/articles/PMC1279826/)

[8]. Rajesh Ramachandran and J. Sujatha Malini (2018). Scientifically practiced interventions for Autism Spectrum Disorder. Int. J. Adv. Res. 6(8), 1238-1242 ISSN: 2320-5407, article DOI:10.21474/IJAR01/7636 DOI URL: http://dx.doi.org/10.21474/IJAR01/7636

[9]. Simpson, R.L 2005. Autism Spectrum Disorders- Interventions and treatments for Children and youth. Sage Publications India Pvt Ltd. ISBN: 978-81-7829-912-9

[10]. Stidham, K. M (2015). General Education Teachers' Perceptions of Educating Students with an Autism Spectrum Disorder in an Inclusive Classroom retrieved from https://etd.ohiolink.edu/!etd.send file?accession=dayton $1437420783 \& d$ isposition=inline

[11]. Strong, J E (2014). Preparing Teachers of Students with Autism Spectrum Disorders: Evidence-Based Practices and Teacher Self-Efficacy, Doctoral dissertation retrieved from https://scholarscompass.vcu.edu/cgi/viewcontent.cgi?article $=4685 \&$ cont ext=etd

[12]. http://www.autism-india.org/

[13]. http://www.rehabcouncil.nic.in/

[14]. https://www.cdc.gov/ncbddd/autism/data.html

[15]. https://www.nationalautismresources.com/the-picture-exchange-commu nication-system-pecs/

[16]. https://data2.unhcr.org/en/documents/download/58557 